\title{
A comparison of maximum inspiratory and expiratory flow in health and in lung disease
}

\author{
J. JOR D A NOGLOU AND N. B. PRIDE \\ From the M.R.C. Clinical Pulmonary Physiology Research Unit, King's College Hospital Medical School, \\ Denmark Hill, London, S.E.5
}

\begin{abstract}
Maximum flow-volume (M.F.-V.) curves for both inspiration and expiration have been obtained in healthy subjects and in patients with bullous emphysema, exacerbation of asthma, and with severe fibrosis of the lungs. The tracheobronchial collapse pattern on the conventional spirogram or the M.F.-V. curve appeared to be related to the severity of airways obstruction more than to the type of airways obstruction. The pattern was observed in exacerbation of asthma as well as in emphysema and occurred when forced expirations were started from low in the vital capacity in normal subjects. The expiratory M.F.-V. slope was normal or steeper than normal in fibrosis and was much lower than normal in asthma and emphysema. In patients with fibrosis maximum expiratory flow (M.E.F.) and maximum inspiratory flow (M.I.F.) at $50 \%$ of vital capacity were both reduced and the ratio between them was similar to that in healthy subjects. In both asthma and emphysema there was a low M.E.F.5\%\% ${ }_{5 \%} /$ M.I.F.50\% $_{\cdot 5}$ ratio ; the only patient with airways obstruction who had a normal M.E.F./M.I.F. ratio was a woman with tracheal stenosis. A theoretical analysis suggests that most forms of airways obstruction would be expected to lead to a greater impairment of M.E.F. than of M.I.F. The M.F.-V. curve did not help in distinguishing a patient with asthma from one with emphysema, but the changes in tracheal obstruction were distinctive.
\end{abstract}

Conventional spirometric tests have not been very helpful in distinguishing between different clinical types of airways obstruction. We have studied the maximum effort flow-volume curves, both inspiratory and expiratory, of subjects with emphysema, asthma, and fibrosis of the lungs to see whether such curves reveal changes of diagnostic significance which are not discernible on conventional spirometric tests. In particular, we have compared the ratio of maximum expiratory flow to maximum inspiratory flow, since it is frequently suggested that in asthma there is both inspiratory and expiratory airflow obstruction, whereas in emphysema expiratory obstruction is the dominant abnormality.

\section{METHODS}

FLOW-VOLUME CURVES AND SPIROMETRIC TESTS The subject breathed through a Fleisch pneumotachograph screen into a light-weight spirometer. The pressure drop across the screen was measured by a Sanborn 270 transducer. The $95 \%$ response time of the pneumotachograph-transducer system was less than $20 \mathrm{msec}$. Volume was obtained by recording the output of a low-torque potentiometer on the spirometer pulley. Both outputs were recorded against time on a Sanborn ultra-violet recorder. Wide-bore tubing was used throughout $\stackrel{x}{\circ}$ and the mouthpiece position was fixed so that the 3 subject was seated without undue flexion or extension of the neck and spine. The mouthpiece had a circular orifice of internal diameter $2.3 \mathrm{~cm}$. After the slow expiratory vital capacity (V.C.) had been measured the subjects made a series of $\frac{D}{0}$ forced expirations from the position of full inspiration into the pneumotachograph-spirometer $\tilde{N}$ system and then a series of forced inspirations $N$ starting from the position of full expiration. We $\mathrm{N}$ encouraged them to make a maximum and sus- $\omega$ tained effort throughout inspiration. These manœuvres were repeated until three closely $\stackrel{\circ}{\complement}$ similar forced expirations and inspirations had $\stackrel{\mathbb{D}}{\mathbb{P}}$ been recorded. We always discarded the first three? expiratory efforts and usually the first five or six inspiratory efforts.

From these records we plotted maximum expira- $\frac{\Omega}{8}$ tory flow and maximum inspiratory flow (M.E.F., 응 M.I.F.) against lung volume throughout the V.C. 
to obtain maximum effort flow-volume (M.F.-V.) curves. In our earlier studies these curves were plotted from the records versus time. Subsequently we have plotted gas flow on the y axis and volume on the $\mathrm{x}$ axis of a storage oscilloscope and traced the curves directly. As discussed in the preceding paper, in some subjects maximum effort manœuvres result in lower levels of expiratory flow than occur with a less forceful expiration; in these cases maximum effort flow-volume curves would not indicate true maximum flow. However, our concern was to study flow-volume relations during the commonly used forced vital capacity manœuvre.

The features of a normal M.F.-V. curve are shown in Fig. 3 of the preceding paper (p. 36). We have analysed these curves under three headings.

Qualitative description of the complete M.F.-V. curve.

The slope of the expiratory M.F.-V. curve The slope $(\Delta M$ M.E.F. $/ \Delta V$.) of expiratory M.F.-V. curves was calculated from the change in flow between $60 \%$ and $40 \%$ of V.C. and expressed as litres/ minute per litre change in lung volume.

Comparisons of expiratory and inspiratory flow We compared M.E.F. at $50 \%$ of the slow expiratory V.C. (M.E.F. ${ }_{50 \%}$ ) with M.I.F. at the same lung volume (M.I.F.5.50). The inspiratory V.C. was greater than the expiratory V.C. in many of the patients with airways obstruction, but we have assumed that the lung volume at full inspiration before a forced expiration was the same as at the end of forced inspiration. As there was little change in M.I.F. between $40 \%$ and $60 \%$ of the V.C. any error due to this assumption should be small. We also obtained peak expiratory and inspiratory flows (P.E.F., P.I.F.) from these curves.

From the simultaneous records of volume versus time on the U.V. recorder we recorded the best values of forced expiratory volume and forced inspiratory volume in one second (F.E.V.1.0, F.I.V.1.0). Normal values for F.E.V.1.0 were predicted from the formula of Kory, Callahan, Boren, and Syner (1961) for men, and of Kory, Smith, and Callahan (to be published) for women.

We have followed the nomenclature for the various spirometric and flow-volume tests recently recommended by Hyatt (1965). All gas volumes were corrected to B.T.P.S.
TOTAL LUNG CAPACITY AND SUB-DIVISIONS These were measured by the closed-circuit helium dilution method (Gilson and Hugh-Jones, 1949). Normal values were predicted from the formulae of Goldman and Becklake (1959).

CARBON MONOXIDE DIFFUSING CAPACITY (Dlco)TRANSFER FACTOR This was measured by the singlebreath method of Ogilvie, Forster, Blakemore, and Morton (1957), except that we used the method of calculating breath-holding time suggested by Jones and Meade (1961). We compared our results with the normal values of Hamer, Cotes, and Meade (see Cotes, 1965) for men and of Newman (1963) for women. The values of Dico in a series of 25 healthy subjects studied in this laboratory agreed closely with these predictions, the mean value being $98 \%$ of those predicted.

\section{SELECTION OF PATIENTS}

NORMAL SUBJECTS We have divided these into two groups: (a) young adults. Three men and five women (ages 19 to 35, mean 26 years) were selected from those working in the laboratory; (b) middle-aged men. Seven men (ages 41 to 48, mean 44 years) were studied.

None of these subjects had a past history of any serious chest illness and none complained of chronic cough, expectoration or undue breathlessness. All had an F.E.V.1.0 and V.C. in excess of $80 \%$ of predicted values and an F.E.V.1.0 /V.C. $\%$ greater than $68 \%$.

BULLOUS EMPHYSEMA AND CHRONIC BRONCHITIS Seven men and one woman (ages 43 to 64, mean 49.6 years) were studied. All these patients had radiological evidence of bullae, chronic expectoration, and evidence of generalized airways obstruction (F.E.V ${ }_{\cdot 1 \cdot 0}$ less than $50 \%$ of predicted value with a mean value of 0.78 litre, F.E.V.1.0 $/$ V.C. $\%$ less than $55 \%$, and residual volume (R.V.) more than $45 \%$ of the T.L.C.). The Dico was less than $62 \%$ of the predicted value in six of the eight subjects.

REVERSIBLE AIRWAYS OBSTRUCTION (ASTHMA) Eight subjects were studied, six women and two men. The ages ranged from 17 to 56 , with a mean of 36.4 years. All gave a history of paroxysmal wheezing attacks interspersed with periods of complete symptomatic remission in which they had neither undue breathlessness nor chronic cough and expectoration. We have analysed only the M.F.-V. curves obtained when asthma was severe and the F.E.V..$_{\cdot 1 \cdot 0}$ was less than $40 \%$ of the 


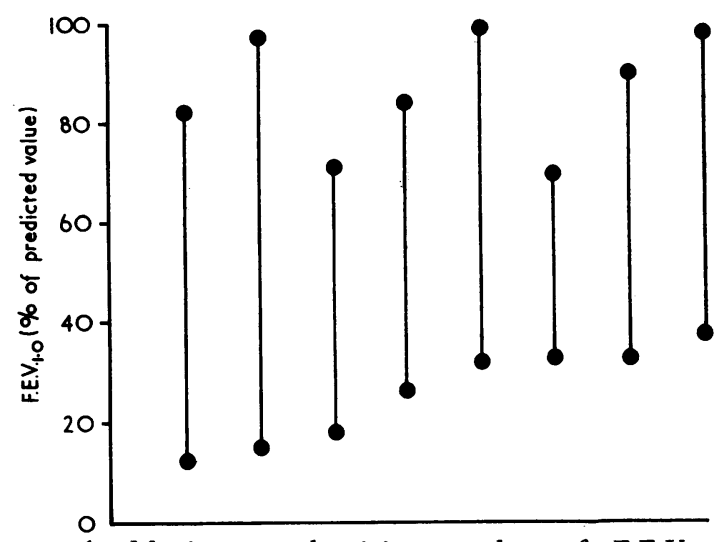

FIG. 1. Maximum and minimum values of F.E.V.1.0 (expressed as $\%$ of predicted value) observed in the eight subjects with asthma. In all patients the change in F.E.V.1.0 was at least $1.3 \mathrm{l}$.

predicted value (mean value of F.E.V $\cdot_{\cdot 1 \cdot 0}=0 \cdot 92$ litre). Expiratory airways obstruction at the time of study was therefore nearly as severe as in the patients with bullous emphysema. Our criterion of variability was that the F.E.V ${ }_{\cdot 1 \cdot 0}$ must have been observed to vary by at least one-third of the predicted value. In most of the patients it varied considerably more than this (see Fig. 1). In all, Dico was more than $90 \%$ of the predicted value when measured in remission.

FIBRosis Seven women and two men (ages 29 to 68 , mean 48.9 years) were studied. All had dyspnoea on mild effort and in all the chest radiograph showed widespread nodulation and reticulation which had been present for at least one year. These patients all had a T.L.C. less than $80 \%$ and a Duco less than $65 \%$ of the predicted value, while the F.E.V. $._{\cdot \cdot 0} /$ V.C. $\%$ was more than $70 \%$. Five of these patients had sarcoidosis, two had rheumatoid arthritis, one had scleroderma, and in the remaining patient fibrosis followed tuberculosis.

\section{RESULTS}

QUALITATIVE CHANGES IN THE COMPLETE M.F.-V. CURVE Typical curves in the four groups are shown in Figure 2. In normal subjects M.E.F. was greater than M.I.F. in about the upper third of V.C. and was less than M.I.F. in the lower twothirds of V.C. A similar relationship was found in fibrosis, but in severe asthma and in emphysema M.I.F. was greater than M.E.F. through almost all the V.C.
Inspiratory M.F.-V. curves showed variations in the values of M.I.F. but not in contour. There were more distinctive changes in the expiratory M.F.-V. curves. In young healthy subjects the decelerating limbs of the expiratory curves (between the volume at which P.E.F. was achieved and R.V.) tended to be slightly convex upwards, whereas in middle-aged normals this part of the curve tended to be slightly concave downwards. In patients with fibrosis, expiratory curves were nearly linear with a normal or above normal slope. The expiratory M.F.-V. curves in the subjects with emphysema all showed a marked concavity upwards with a transition from P.E.F. to

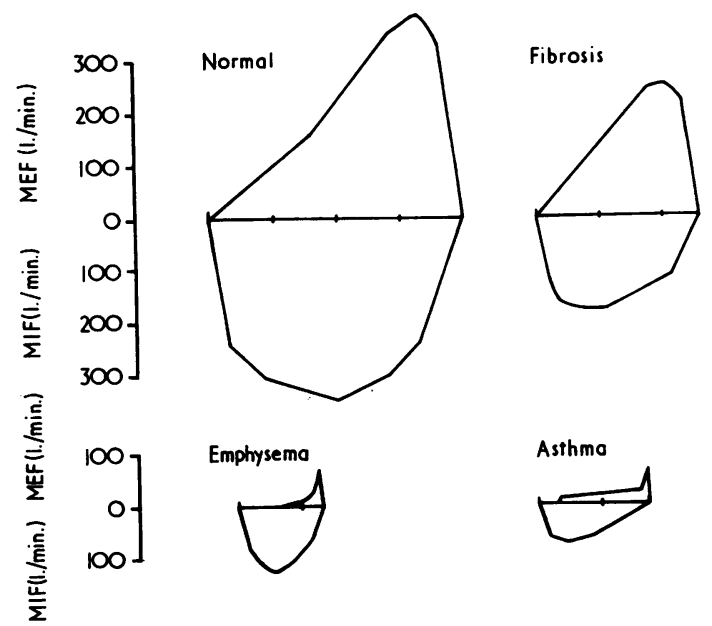

FIG. 2. Representative M.F.-V. curves for the four groups.

a very much reduced level of flow over a very small change in lung volume. The remainder of the V.C. down to R.V. was expelled at a flow rate which changed very little with lung volume and with time. The curves were similar in severe exacerbation of asthma although the rapid reduction in flow over the upper part of the V.C. was usually not so striking. This pattern on the flow-volume curve corresponds to the 'tracheobronchial collapse' pattern on the forced expiratory spirogram in which a brief phase of rapid expiration is followed by a sharp inflection and a prolonged phase of slow volume change (Gandevia, 1963).

Serial M.F.-V. curves showed that in the patients with asthma this pattern disappeared in remission (Fig. 3). The appearance of tracheo-bronchial collapse could also be produced in normal 


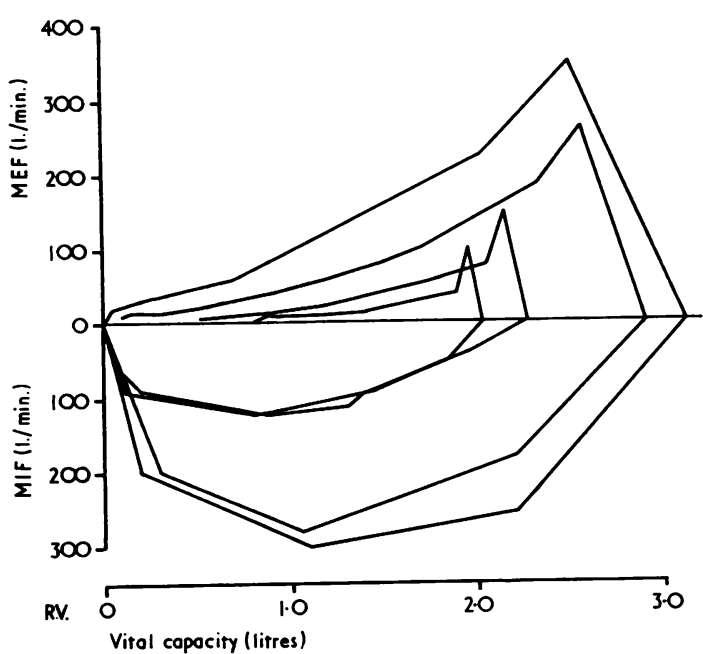

FIG. 3. Successive M.F.-V. curves obtained in a 31-yearold woman as she recovered from an exacerbation of asthma. All are plotted from the same R.V. point. As the attack remitted, V.C., P.E.F., and P.I.F. all increased and the tracheobronchial collapse pattern disappeared.

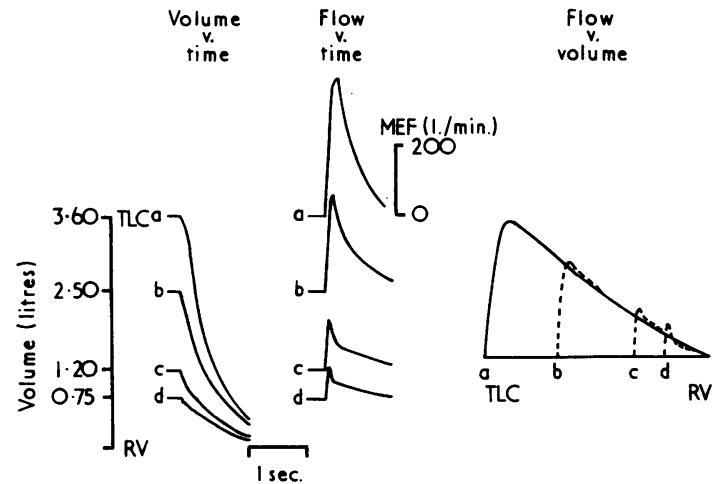

FIG. 4. Forced expirations begun from various volumes above R.V. in a normal subject. The tracheobronchial collapse pattern could be seen on all three piots when forced expiration commenced from 0.75 l. above R.V. (d). The position of full inspiration (T.L.C.) is on the left of this M.F.-V. curve. subjects who made forced expiratory efforts from volumes in the lower part of the V.C. (Fig. 4). Patients with asthma, who did not show the pattern on forced expiration from full inspiration, frequently did so from volumes in the middle of the V.C. It appeared that the characteristic pattern could be produced by all subjects close to R.V. ; as airways obstruction became more severe the pattern became evident higher in the V.C. until it was seen on forced expiratory effort from T.L.C.

In both groups with airflow obstruction P.E.F. was achieved closer to T.L.C. (as measured on the spirometer) than in the healthy subjects.

SLOPE OF EXPIRATORY M.F.-V. CURVES (see Table) The slopes were significantly reduced below normal in both asthnia and emphysema $(P<0.01$ in both cases); the highest values of slope were found in patients with fibrosis, but these were not significantly different from the values in middleaged normal subjects $(\mathbf{P}>0 \cdot 05,<0 \cdot 10)$.

COMPARISONS OF EXPIRATORY AND INSPIRATORY FLow In almost all the normal subjects M.E.F. ${ }_{50 \%}$ was less than M.I.F. ${ }_{50 \%}$ (Fig. 5). The absolute values of M.E.F..$_{50 \%}$ and M.I.F. ${ }_{50 \%}$ (and also of P.E.F. and P.I.F.) were reduced below normal in all three groups of patients. In both groups with airways obstruction the M.E.F. ${ }_{50 \%} /$ M.I.F. ${ }_{50 \%}$ ratio was significantly reduced from normal ( $P<0.01$ in each case), but the lowest ratios were found in subjects with emphysema, in six of whom M.I.F. ${ }_{50 \%}$ was more than 10 times as great as M.E.F. ${ }_{50 \%}$. The patients with fibrosis, with one exception, showed a normal M.E.F. ${ }_{50 \%} /$ M.I.F. $_{{ }_{50} \%}$ ratio. There was no overlap of M.E.F. ${ }_{50 \%}$ l M.I.F.50\% ratios between normal subjects and patients with airways obstruction. The P.E.F./ P.I.F. and F.E.V ${ }_{\cdot 1 \cdot 0} /$ F.I.V $_{\cdot 1 \cdot 0}$ ratios, on the other hand, showed much poorer discrimination between the various groups (see Table) and did

T A B L E

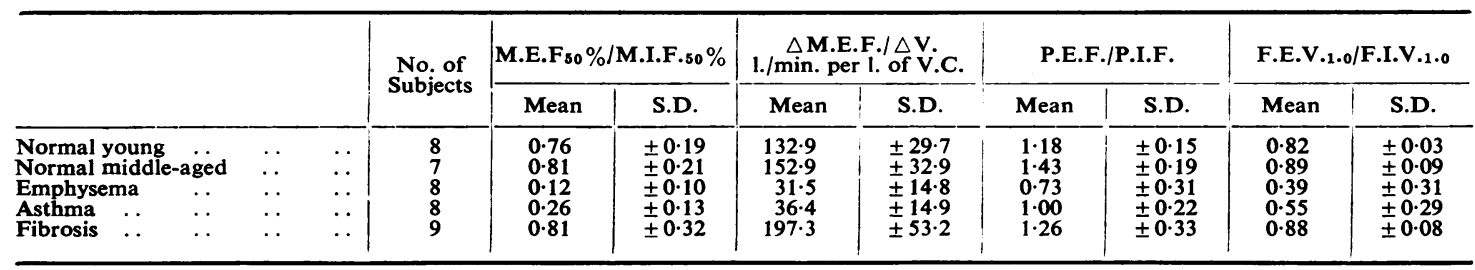




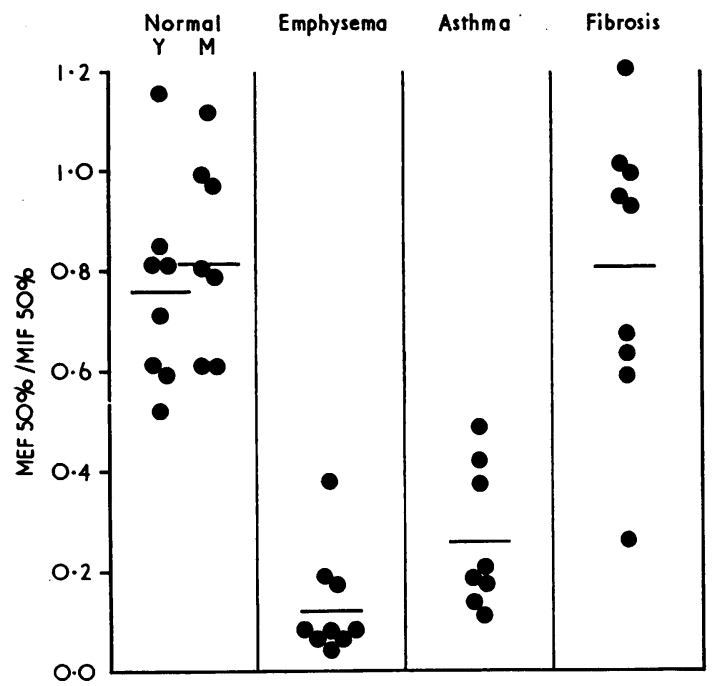

FIG. 5. M.E.F. ${ }_{50} \% / M . I . F_{{ }_{50}} \%$ ratios in the four groups. $Y$, young; $M$, middle-aged.

not indicate the tremendous disparity that existed between M.E.F. and M.I.F. over much of the V.C. in emphysema.

\section{DISCUSSION}

The striking feature of the results was the similarity between asthma and emphysema. We attempt to explain this finding below by referring to the theoretical analysis set out in the preceding paper. The terms and abbreviations used were introduced and defined in the preceding paper.

LIMITATIONS OF METHOD Values of M.I.F., being entirely effort dependent, will be affected by the external load imposed by the measuring system to a greater extent than values of M.E.F. In addition, Harris (1959) has pointed out that forced inspiration is influenced by the position of the neck and trunk ; for this reason we used a fixed mouthpiece to limit movement of the subject. The spirometer we used did not significantly alter the M.F.-V. curves. This was checked in three subjects by comparing curves obtained using the usual spirometer bell with curves in which volume was obtained either by integration of the flow trace without using a bell or by use of a volume displacement body plethysmograph (Mead, 1960). The position of the mouthpiece was important. We used a conventional mouthpiece with a large gumshield for all our comparisons; but this will have led to an underestimate of true P.I.F. since in six subjects the values of P.I.F. averaged $10 \%$ higher when a mouthpiece of similar internal diameter was inserted beyond the teeth.

We used an unstandardized technique of 'training' subjects until consistent inspirations were produced. In the three breaths analysed in detail after discarding practice runs, the values of M.I.F. $50 \%$ usually lay within $10 \mathrm{l} / \mathrm{min}$. when M.I.F. ${ }_{50 \%}$ was less than $200 \mathrm{l} . / \mathrm{min}$. and within 15-20 1./min. when M.I.F. ${ }_{50 \%}$ was greater than $200 \mathrm{1} . / \mathrm{min}$. In fact, in our results the coefficient of variation was greater for M.E.F.5n\% than for M.I.F. ${ }_{50 \%}$, but this was influenced by the 'training' technique and the lower values of M.E.F. ${ }_{50 \%}$ in patients. To obtain a more valid comparison we measured the variability of P.E.F. and P.I.F. in six healthy medical students using a modified Wright peak flow meter (Nairn and McNeill, 1963) and a standard technique. We obtained three measurements (after discarding two practice attempts) of P.E.F. and P.I.F. on four successive days. In these subjects mean P.E.F. was $10 \%$ higher than mean P.I.F. The average coefficient of variation was $3.4 \%$ for P.E.F. and $5.5 \%$ for P.I.F.

The method, therefore, appeared reasonably repeatable but will have underestimated true M.I.F. This error will have caused us to underestimate the difference between M.I.F.50\% and M.E.F. ${ }_{50 \%}$ in asthma and emphysema.

SIGNIFICANCE OF 'TRACHEOBRONCHIAL COLLAPSE' PATTERN Gandevia (1963) has shown that the spirometric pattern of 'tracheobronchial collapse' is usually accompanied by bronchographic and bronchoscopic evidence of extensive narrowing of large airways on forced expiration. Such extensive narrowing would develop when alveolar pressure exceeded $\mathrm{Palv}^{\prime}$. It appears possible that the transient peak of flow occurs during the time it takes for the large airways to move from their relatively distended position at end-inspiration to the posi- $\sigma$ tion in which they limit M.E.F. by acting as a $N$ Starling resistor. Production of the characteristic N spirogram would then depend on (1) the ability to generate an alveolar pressure greater than Palv' early in expiration; and (2) a large difference be- $\stackrel{\varrho}{\subset}$ tween the P.E.F. and the M.E.F. achieved when $\stackrel{\mathbb{D}}{\sim}$ the flow-limiting mechanism is established on expiration.

If this interpretation is correct, the pattern will $\stackrel{\vec{D}}{\vec{D}}$ occur whenever the values of both Palv' $^{\prime}$ and $\stackrel{?}{\mathbb{D}}$ M.E.F. are reduced; this is the case close to full 2 inflation in asthma and in emphysema. The same 
explanation would account for the finding (recently reported also by Tammeling, Berg, and Sluiter, 1966) that the pattern can be produced by healthy subjects who make a forceful expiration from low in the V.C. Our results suggest that the spirographic pattern of tracheobronchial collapse is primarily a consequence of severe airways obstruction. Although the pattern may be more pronounced in emphysema the differences are not sufficiently great to distinguish this condition from other types of airways obstruction.

CHANGES IN $\Delta$ M.E.F. $/ \Delta$ V. SLOPE In the preceding paper we suggested that this slope, at least in the middle of the vital capacity, approximated to $I / C_{L}$.Rs. If this is the case then loss of volume from a normal lung (such as after lobectomy) should not alter the $\Delta$ M.E.F. $/ \Delta V$. slope, since $C_{L}$ will be reduced and Rs increased equally. We have not been able to study the effects of lohectomy but we have obtained M.F.-V. curves in a young man before and after decortication of a left fibrothorax (Fig. 6). This man had no evidence of

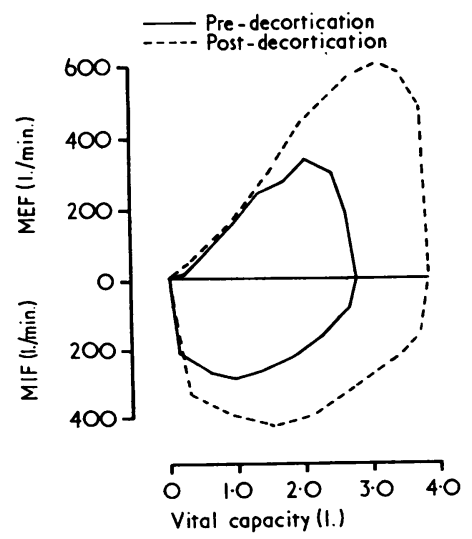

FIG. 6. M.F.-V. curves in a 29-year-old man before and after decortication of the left lung, plotted from the same R.V. point.

parenchymal lung disease. Before operation measurements of lobar gas flow showed very poor ventilation of the left lung, but this was much improved following decortication. After operation the values of P.E.F., P.I.F., and V.C. all increased but the $\Delta$ M.E.F. $/ \Delta$ V. slope was unchanged, indicating, we believe, that improvement was due to the recruitment of normal parallel units in the left lung. In general, however, we did not find the $\Delta$ M.E.F./ $\Delta$ V. slope to be as constant between different normal subjects as Dayman (1961) inferred from spirometric records. We have not made a systematic study of normal subjects of different sizes, but a $2.08 \mathrm{~m}$. (6 ft. $10 \mathrm{in}$.) young man showed a lower slope and a $1 \cdot 19 \mathrm{~m}$. $(3 \mathrm{ft}$. 11 in.) 80-year-old circus dwarf showed a higher slope than any of our young normal subjects.

Although the mean slope in the subjects with fibrosis was not significantly different from that in the healthy subjects, four subjects with fibrosis had steeper slopes than any of the normals. An abnormally steep slope indicates that $C_{L}$ was reduced more than expected from the loss of parallel units alone; measurements of this slope might be a simple method of picking out those subjects whose lungs are abnormally stiff as well as small.

In airways obstruction it is more difficult to interpret the $\Delta$ M.E.F. $/ \Delta$ V. slope. The slope will be reduced by an increased $R s$ or an increased $C_{L}$ but, using the present method, the expiratory M.F.-V. curve is also dependent on regional variations in the rate of emptying. In this study we found (as had Macklem and Becklake in 1963) a low slope in severe asthma as well as in emphysema. This contrasts with a previous study (Pride, Permutt, Riley, and Bromberger-Barnea, 1967) in which a relatively normal $\Delta$ M.E.F. $/ \Delta$ V. slope was found in asthma; some of this discrepancy will have arisen because the method used in the previous study was not sensitive to different rates of regional emptying and some because their patients had less severe asthma at the time of study.

CHANGES IN M.E.F. ${ }_{50 \%} /$ M.I.F ${ }_{50} \%$ RATIO IN AIRWAYS OBSTRUCTION LOW M.E.F. ${ }_{50 \%} /$ M.I.F. ${ }_{50 \%}$ ratios were found both in exacerbation of asthma and in emphysema. In equation (3) of the preceding paper it was shown that the M.E.F. ${ }_{50 \%} /$ M.I.F. ${ }_{50 \%}$ ratio depended not only on the ratio of inspiratory to expiratory resistance but also on the Palv'/ Palv,min ratio. The $\mathrm{Palv}^{\prime} / \mathrm{Palv}$,min ratio will be lower than in health in both asthma and emphysema. Palv' has been shown to be low in emphysema (Fry, Ebert, Stead, and Brown, 1954) and in exacerbation of asthma (Campbell, Martin, and Riley, 1957 ; Pride et al., 1967). Muscular power in both conditions is usually normal, so that Palv,min is likely to be at least as negative as in healthy subjects and may be more negative if inspiratory resistance is high (Agostoni and Fenn, 1960). The presence of a low Palv'/Palv, min ratio in both conditions makes it impossible to use the M.E.F. ${ }_{50 \%} /$ M.I.F. $_{50 \%}$ ratio to distinguish the individual subject with asthma from 
another with emphysema. The tendency to a somewhat higher M.E.F. ${ }_{50 \%} /$ M.I.F. $_{50 \%}$ ratio in exacerbation of asthma may reflect a relatively greater increase in inspiratory resistance (as has been reported by Ting and Williams (1963)). On the other hand, this difference may be due in part to the less severe expiratory obstruction in the subjects with asthma, since in general we found that the lowest M.E.F. ${ }_{50 \%} /$ M.I.F. $_{50 \%}$ ratios were found when expiratory airways obstruction was most severe.

Airways obstruction is likely to result in equal reduction in M.E.F. and M.I.F. at $50 \%$ V.C. only if there is no associated reduction in the value of Palv'. Equation (4) in the preceding paper shows that in most forms of airways obstruction Palv' will be reduced. Even if airways narrowing affected segments $\mathrm{D}$ and $\mathrm{S}$ equally, it is probable that the ratio $R d / R s$ would be lower than in health because the occurrence of turbulence increases Rd disproportionately at the large flows which the normal subject produces. Palv' is likely to be raised only when there is a greater increase in Rd than in Rs. This change can be produced in a normal subject by placing an obstruction in the mouthpiece, and the changes this produces in the M.F.-V. curve are shown in Figure $7 \mathrm{~b}$. It will be
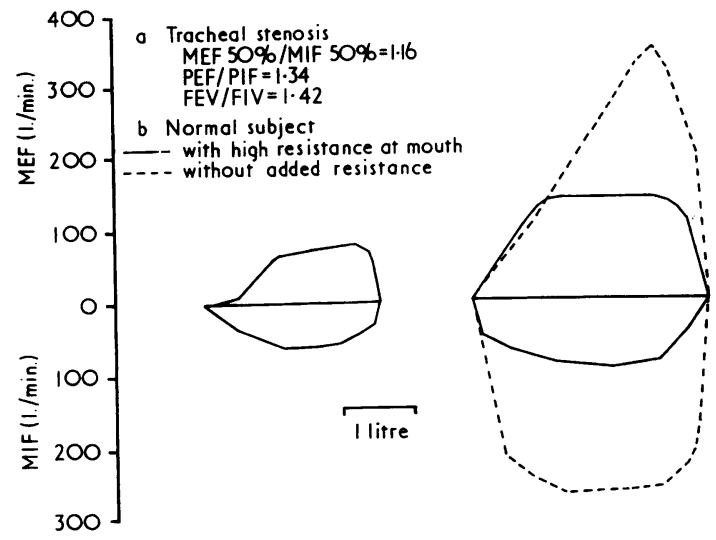

FIG. 7. M.F.-V. curves (a) in a woman with subglottic tracheal stenosis and (b) in a normal subject with and without added resistance at the mouth.

seen that with the added obstruction M.E.F. ${ }_{50 \%}$ was somewhat greater than M.I.F.50\%. Similar changes were found in a 56-year-old woman with sublaryngeal tracheal stenosis (Fig. 7a); her curve was markedly different from those of all the other patients with airways obstruction. We do not know how far down from the larynx airways obstruction can be situated and still give this distinctive 'external resistance' pattern. We have only observed it in this one patient. According to the theory outlined it will occur whenever the obstruction occurs in segment $\mathrm{D}$, which may not extend much further towards the alveoli than the carina. Lichterfeld (1960) has reported that there is an approximately equal impairment of F.I.V.1.0 and F.E.V..$_{\cdot 1 \cdot 0}$ in subjects with central bronchial carcinoma, but we have not had the opportunity to measure M.F.-V. curves in such patients.

\section{CONCLUSIONS}

We did not find the M.F.-V. curve any more helpful than conventional spirometric tests in distinguishing between a subject with asthma and one with emphysema. As with conventional spirometry the changes in the M.F.-V. curve appear to be related to the severity of the airways obstruction rather than to the mechanism causing the obstruction. The only patient in whom the M.F.-V. curve was useful in diagnosis was the woman with tracheal stenosis who would not have been picked out by measurement of the F.E.V ${ }_{\cdot 1 \cdot 0}$ and V.C. In fact, however, she could have been picked out by the use of a combination of conventional tests, for instance by noting that her P.E.F. was much lower than would be expected from the F.E.V.1.0.

Despite these largely negative results we have found a knowledge of the M.F.-V. curve helpful in defining the possibilities and limitations of spirometric tests, since the M.F.-V. curve embraces in a compact form all the tests which are based on the forced vital capacity manœuvre. Although in that sense the M.F.-V. curve provides more information than the F.E.V.1.0 and V.C., the present evidence does not suggest that a great deal would be gained by simply substituting the M.F.-V. curve for the F.E.V $\cdot_{1 \cdot 0}$ in the routine assessment of ventilatory function. But if the M.F.-V. curve is used in combination with other tests, such as the static lung compliance and the total lung capacity, it should prove to be useful in discriminating between the different mechanisms which result in reduced maximum flow.

We are grateful to the various physicians of King's College Hospital and St. Giles' Hospital for allowing us to study their patients, and to Miss L. Chapman, Miss E. Douglas, and Miss M. Rusbridge for excellent technical assistance. 


\section{REFERENCES}

Agostoni, E., and Fenn, W. O. (1960). Velocity of muscle shortening as a limiting factor in respiratory air flow. J. appl. Physiol., 15, 349.

Campbell, E. J. M., Martin, H. B., and Riley, R. L. (1957). Mechanisms of airway obstruction. Bull. Johns Hopk. Hosp., 101, 329.

Cotes, J. E. (1965). Lung Function, p. 342. Blackwell, Oxford.

Dayman, H. (1961). The expiratory spirogram. Amer. Rev. resp. Dis., 83,842 .

Fry, D. L., Ebert, R. V., Stead, W. W., and Brown, C. C. (1954). The mechanics of pulmonary ventilation in normal subjects and in patients with emphysema. Amer. J. Med., 16, 80 .

Gandevia, B. (1963). The spirogram of gross expiratory tracheobronchial collapse in emphysema. Quart. J. Med., N.S., 32, 23.

Gilson, J. C., and Hugh-Jones, P. (1949). The measurement of the total lung volume and breathing capacity. Clin. Sci., 7, 185.

Goldman, H. I., and Becklake, M. R. (1959). Respiratory function tests. Normal values at median altitudes and the prediction of normal results. Amer. Rev. Tuberc., 79, 457.

Harris, R. S. (1959). Tracheal extension in respiration. Thorax, 14, 201.

Hyatt, R. E. (1965). Dynamic lung volumes. In Handbook of Physiology. Section 3: Respiration, vol. ii, p. 1381. American Physiological Society, Washington, D.C.

Jones, R. S., and Meade, F. (1961). A theoretical and experimental analysis of anomalies in the estimation of pulmonary diffusing capacity by the single breath method. Quart.J. exp. Physiol., 46, 131 .
Kory, R. C., Callahan, R., Boren, H. G., and Syner, J. C. (1961) The Veterans Administration-Army Cooperative study of pulmonary function. 1. Clinical spirometry in normal men. Amer. J. Med., 30, 243.

Lichterfeld, A. (1960). Untersuchungen über den inspiratorischen Tiffeneau-Test. Klin. Wschr., 38, 219.

Macklem, P. T., and Becklake, M. R. (1963). The relationship between the mechanical and diffusing properties of the lung in health and disease. Amer. Rev. resp. Dis., 87, 47.

Mead, J. (1960). Volume displacement body plethysmograph for respiratory measurements in human subjects. J. appl. Physiol., $15,736$.

Nairn, J. R., and McNeill, R. S. (1963). Adaptation of the Wright peak flow meter to measure inspiratory flow. Brit. med.J., 1, 1321

Newman, F. (1963). Ph.D. Thesis, London University.

Ogilvie, C. M., Forster, R. E., Blakemore, W. S., and Morton, J. W. (1957). A standardized breath holding technique for the clinica measurement of the diffusing capacity of the lung for carbon monoxide. J. clin. Invest., 36, 1 .

Pride, N. B., Permutt, S., Riley, R. L., and Bromberger-Barnea, B. (1967). Determinants of maximum expiratory flow. J. appl. Physiol., in press.

Tammeling, G. J., Berg, W. Chr., and Sluiter, H. J. (1966). Estimation of the expiratory collapse of the intrathoracic airways. Amer. Rev. resp. Dis., 93, 238.

Ting, E. Y., and Williams, M. H., Jr. (1963). The mechanics of breathing in chronic obstructive pulmonary disease. Ibid., 88, 791. 